\title{
Analysis of wind speed characteristics using different distribution models in Medan City, Indonesia
}

\author{
Suwarno $^{1}$, Ismail Yusuf ${ }^{3}$, M. Irwanto ${ }^{2}$, Ayong Hiendro ${ }^{3}$ \\ ${ }^{1}$ Department of Electrical Engineering, North Sumatera Muhammadiyah University (UMSU), Indonesia \\ ${ }^{2}$ Department of Electrical Engineering, Medan Institute of Technology (ITM), Indonesia \\ ${ }^{3}$ Department of Electrical Engineering, Tanjungpura University, Indonesia
}

\section{Article Info}

Article history:

Received Feb 19, 2021

Revised Mar 5, 2021

Accepted Mar 25, 2021

\section{Keywords:}

Cumulative probability

Exponential distribution

Gamma distribution

Weibull

Wind energy

\begin{abstract}
Estimating wind speed characteristics plays an essential role in designing a wind power plant at a selected location. In this study, the Weibull, gamma, and exponential distribution models were proposed to estimate and analyze the wind speed parameters and distribution functions. Real measured data were collected from Medan City, Indonesia. The scale and shape factors of wind distribution for three years data were calculated. The observed cumulative probability of the three models was compared to predicted wind characteristics. The probability density function (PDF) and the cumulative density function (CDF) of wind speed were also analyzed. The results showed that the Weibull model was the best model to determine PDF, while the exponential model was the best model to determine CDF for the Medan City wind site.
\end{abstract}

This is an open access article under the CC BY-SA license.

\section{Corresponding Author:}

Ayong Hiendro

Department of Electrical Engineering

Tanjungpura University

Jalan Prof. Dr. H. Hadari Nawawi, Pontianak 78124, Kalimantan Barat, Indonesia

Email: ayong.hiendro@ee.untan.ac.id

\section{INTRODUCTION}

Wind energy is one of the cheapest renewable energy, and it is a very large source of energy around the world. The global potential of wind energy is about $10 \mathrm{TW}$, and it can provide the world electricity needs as much as $35 \%$ [1]. According to IRENA reports [2], the world total installed capacity of wind energy is $622.70 \mathrm{GW}$ in 2019. While Asia has reached $40 \%$ of the global installed capacity [3], Indonesia has a total installed capacity of $76 \mathrm{MW}$ in 2019 , and this value is only $0.03 \%$ of the total installed capacity in Asia.

Estimating wind speed characteristics is very important to assess the potential of wind energy [4], evaluate the performance of wind energy systems [5], and design a power plant at a selected location. Moreover, wind energy potential varies directly to the wind speed, and the small changes in wind speed will affect the amount of energy produced by the wind power plant. For these purposes, an appropriate wind model is required to accurately analyze the wind data measured at the site [6] because the wind energy is much related to the site and geographic conditions [7]. Another method to extrapolate wind data precisely is by using a site-specific wind power law [8].

The distribution function is one of the most widely used techniques, and it is vital for the analysis of performance losses in complex systems in engineering. In general, the distribution function can be used to predict and represent a variety of different phenomena. Moreover, it can also be applied to analyze the probability of wind speed. Characterizing the wind speed distribution function becomes simple when the measured histogram is correctly fitted with the analytical data [9]. The wind distribution function at certain 
points can be interpreted as relative likelihood values. The wind distribution function also provides the frequency of wind speed [10], [11]. Wind distribution functions, such as the probability density function (PDF) and the cumulative density function (CDF) of the wind speed, are very crucial to determine the technical feasibility and the economic viability of a power plant project [12].

The popular distribution function to estimate wind energy is the Weibull distribution function. Weibull distribution function consists of shape and scale parameters, which can be calculated using several models available in the literature [13]-[15]. The shape factor identifies the width of the wind speed distribution and determines the peak wind distribution in any region [16]. The scale factor identifies the abscissa scale of wind distribution and the condition of most of the wind potentials in a particular location [17]. Mohammed et al. [18] applied the Weibull distribution function to analyze statistics on the maximum monthly wind speed and the minimum monthly wind speed in Zagora, Morocco. Mahmood et al. [19] also analyzed wind characteristics for the Al-Salman site in Iraq using Weibull distribution.

In the wind energy application, a two-parameter Weibull is widely used and accepted to estimate wind energy potential. The two-parameter Weibull is represented in the form of a computable and flexible mathematical function [20]. Modeling wind speed with a two-parameter Weibull yielded significant values as reported in [21]-[24]. Teimourian et al. [25] applied a two-parameter Weibull to investigate other feasible wind sites in Iran. Sumair et al. [26] used a two-parameter Weibull with energy pattern factor method to estimate Weibull parameters.and assess wind potential in South Punjab. Sumair et al. [27] also compared two-parameter Weibull, Rayleigh, and lognormal distributions to model the wind potential of the coastal belt of Pakistan. The two-parameter Weibull performed the most accurately, and the Rayleigh distribution was found to be the least.

Mert and C. Karakuş [28] used the two-parameter Weibull, mixed Weibull, generalized gamma, and Burr 4-parameter distribution to describe the wind speed profile. They reported that the mixed Weibull distribution had a better match compared to the two-parameter Weibull [29]. In addition, estimating wind performance and assessment of the wind energy potential in wind energy planning projects using the twoparameter Weibull was not suitable for large-scale wind energy generation [10]. Three-parameter generalized gamma distribution [30] and normal distribution [31] were found to more accurately describe the wind characteristics compared to the two-parameter Weibull at different locations. Kollu et al. [32] developed a wind speed model based on Rayleigh and Weibull distributions. However, Weibull empirical data showed low confidence in the results, which prompted researchers to suggest various alternative analytic distributions, such as Gaussian inverse [33], lognormal [34], normal square root [35], Weibull inverse [36], the principle of maximum entropy [37], and Weibull-gamma composite [38]. Arreyndip et al. [39] suggested the general extreme distribution to analyzed wind energy variation and potential. In recent years several studies have been conducted to assess the potential for wind energy potential by using single and mixed distributions [35], [36].

It is obvious that no particular model fits all cases. For different wind locations, investigations should be carried out to obtain a suitable model for designing a wind power plant [40]. The Weibull distribution was the most used to determine the PDF of wind speed. The gamma and exponential distribution were often employed to determine the PDF of wind speed. However, there was still not enough information available about which model among the Weibull, gamma, and exponential distributions, is suitable to estimate PDF and CDF of the wind speed. This study aimed to propose and compare the three aforementioned models in estimating the best distribution functions of the wind speed characteristics in Medan City, Indonesia.

\section{RESEARCH METHOD}

In this study, the wind speed data was collected at Medan City $\left(2^{\circ} 27^{\prime}-2^{\circ} 47^{\prime} \mathrm{N}, 98^{\circ} 35^{\prime}-98^{\circ} 44^{\prime} \mathrm{E}\right)$, Indonesia. The historical monthly wind speed data for 2017-2019 was used to estimate the wind distribution function. Figure 1 shows daily wind speed from January 2017 to December 2019. Medan City is located at 2.5-37.5 meters above sea level and has significant wind potential. Medan City has a tropical rainforest climate with dry and wet seasons that are not very distinct. Medan City has the driest months from February to April and experiences the wettest month in October [41]. The average wind speed in Medan City is around $3.16 \mathrm{~m} / \mathrm{s}$ with a standard deviation of 0.30433 [42].

\subsection{Wind distribution functions}

Three distribution function models were proposed to evaluate wind speed in Medan City, namely the Weibull, gamma, and exponential distribution functions. Each distribution function has its own probability distribution function (PDF) and cumulative distribution function (CDF). The PDF is used to 
determine the probability of a random variable falling within a specific range of values. In contrast, the CDF is used to determine the distribution of multivariate random variables.

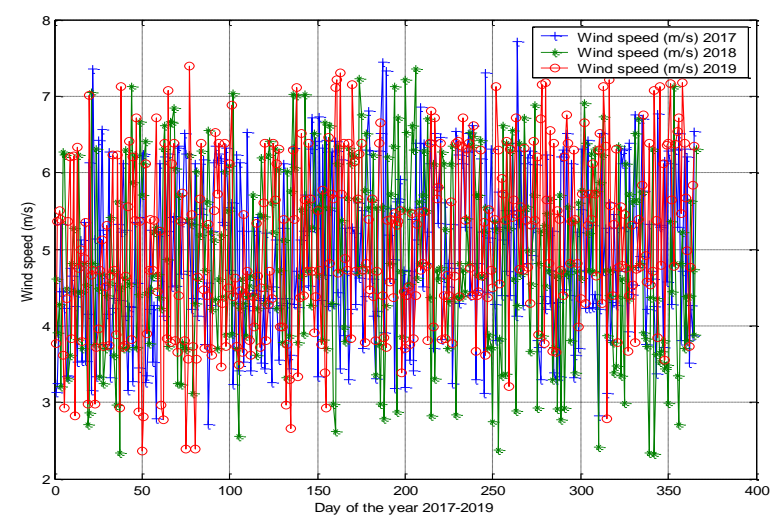

Figure 1. Daily wind speed at Medan City for three years

Weibull distribution function has the PDF as follows:

$$
f(v)=\frac{k}{c}\left(\frac{v}{c}\right)^{k-1} \exp \left[-\frac{v}{c}\right]^{k}, k>0, v>0, c>0
$$

The corresponding CDF of the Weibull distribution function is defined by

$$
F(v)=1-\exp \left[-\frac{v}{c}\right]^{k}, k>0, v>0, c>0
$$

where $c$ and $k$ are the scale and shape factors, respectively, and $v$ is the observed wind speed (m/s).

Like the Weibull distribution, the gamma distribution function also has two parameters, i.e., a scale factor $c>0$ and a shape factor $k>0$ to control the wind speed distribution. The gamma PDF and CDF at observed wind speed $v$ are defined by:

$$
\begin{aligned}
& f(v)=\frac{1}{c^{k} \Gamma(k)} v^{k-1} \exp \left[-\frac{v}{c}\right], k>0, v>0, c>0 \\
& F(v)=\int_{0}^{a} \frac{1}{c^{2}} v \cdot \exp \left[-\frac{v}{c}\right] d v, v>0, a \in(0, \infty)
\end{aligned}
$$

where $\Gamma(\alpha)$ is the gamma function:

$$
\Gamma(k)=\int_{0}^{\infty} v^{k-1} e^{-v} d v, v>0
$$

Different from the Weibull and gamma distributions, the exponential distribution function has only one parameter to control the wind speed distribution, i.e., a scale factor $c>0$. The exponential PDF and CDF at observed wind speed $v$ are described as follows:

$$
\begin{aligned}
& f(v)=\frac{1}{c} \exp \left[-\frac{v}{c}\right], v>0, c>0 \\
& F(v)=1-\exp \left[-\frac{v}{c}\right], v>0
\end{aligned}
$$

In a statistical method, the maximum likelihood (ML) can be applied to estimate the parameters of a probability distribution by maximizing a likelihood function [43]. According to this method, the shape $(k)$ and scale $(c)$ parameters are calculated to the total data points $(N)$, as follows [44], [45]: 


$$
\begin{aligned}
& k=\left[\frac{\sum_{i=1}^{N} v_{i}^{k} \ln \left(v_{i}\right) f\left(v_{i}\right)}{\sum_{i=1}^{N} v_{1}{ }^{k} f\left(v_{i}\right)}-\frac{\sum_{i=1}^{N} \ln \left(v_{i}\right) f\left(v_{i}\right)}{\sum_{i=1}^{N} f\left(v_{i}\right)}\right]^{-1} \\
& c=\left[\frac{1}{\sum_{i=1}^{N} f\left(v_{i}\right)} \sum_{i=1}^{N} v_{i}^{k} f\left(v_{i}\right)\right]^{\frac{1}{k}}
\end{aligned}
$$

\section{RESULTS AND DISCUSSION}

In this section, three proposed models, i.e., Weibull, gamma, and exponential, are applied to analyze wind speed parameters (scale and shape). The estimated wind speed distribution parameters of each model for the three years (2017-2019) are presented in Table 1, Table 2, and Table 3. Additionally, the yearly wind speed distribution parameters for 2017, 2018, and 2019 are also shown in the last row of Table 1, Table 2, and Table 3, respectively.

Table 1. Estimated distribution parameters of wind speed for 2017

\begin{tabular}{lccccc}
\hline & \multicolumn{2}{c}{ Weibull distribution } & \multicolumn{2}{c}{ Gamma distribution } & Exponential distribution \\
& Scale $(c)$ & Shape $(k)$ & Scale $(c)$ & Shape $(k)$ & Scale $(c)$ \\
\hline January & 4.849 & 4.897 & 3.794 & 16.871 & 0.225 \\
February & 5.343 & 4.667 & 3.593 & 17.560 & 0.205 \\
March & 5.549 & 4.930 & 3.766 & 19.169 & 0.196 \\
April & 5.049 & 5.729 & 5.280 & 24.674 & 0.214 \\
May & 5.717 & 5.820 & 4.873 & 25.817 & 0.189 \\
June & 5.834 & 4.783 & 3.820 & 20.391 & 0.187 \\
July & 5.848 & 4.373 & 3.157 & 16.798 & 0.188 \\
August & 5.848 & 5.056 & 4.194 & 21.324 & 0.197 \\
September & 5.536 & 4.306 & 3.131 & 14.993 & 0.209 \\
October & 5.261 & 4.631 & 3.690 & 17.484 & 0.211 \\
November & 5.449 & 4.572 & 3.472 & 17.280 & 0.201 \\
December & 4.585 & 4.556 & 3.525 & 14.767 & 0.239 \\
Yearly & 5.373 & 4.560 & 4.356 & 21.618 & 0.202 \\
\hline
\end{tabular}

Table 2. Estimated distribution parameters of wind speed for 2018

\begin{tabular}{lccccc}
\hline & \multicolumn{2}{c}{ Weibull distribution } & \multicolumn{2}{c}{ Gamma distribution } & Exponential distribution \\
& Scale $(c)$ & Shape $(k)$ & Scale $(c)$ & Shape $(k)$ & Scale $(c)$ \\
\hline January & 4.849 & 4.897 & 3.794 & 16.871 & 0.225 \\
February & 5.318 & 4.744 & 3.687 & 17.952 & 0.205 \\
March & 5.573 & 4.959 & 3.835 & 19.601 & 0.196 \\
April & 5.029 & 5.722 & 5.296 & 24.638 & 0.215 \\
May & 5.757 & 5.857 & 4.985 & 26.601 & 0.187 \\
June & 5.857 & 4.747 & 3.772 & 20.201 & 0.187 \\
July & 5.867 & 4.341 & 3.099 & 16.537 & 0.187 \\
August & 5.456 & 5.187 & 4.457 & 22.365 & 0.199 \\
September & 5.354 & 4.161 & 2.905 & 14.128 & 0.206 \\
October & 5.097 & 4.834 & 4.146 & 19.356 & 0.214 \\
November & 5.490 & 4.540 & 3.455 & 17.312 & 0.200 \\
December & 4.611 & 4.459 & 3.348 & 14.084 & 0.238 \\
Yearly & 5.347 & 4.916 & 3.556 & 17.448 & 0.204 \\
\hline
\end{tabular}

Table 3. Estimated distribution parameters of wind speed for 2019

\begin{tabular}{lccccc}
\hline & \multicolumn{2}{c}{ Weibull distribution } & \multicolumn{2}{c}{ Gamma distribution } & Exponential distribution \\
& Scale $(c)$ & Shape $(k)$ & Scale $(c)$ & Shape $(k)$ & Scale $(c)$ \\
\hline January & 5.017 & 4.887 & 3.929 & 18.076 & 0.217 \\
February & 5.389 & 4.053 & 2.805 & 13.702 & 0.205 \\
March & 5.053 & 3.833 & 2.488 & 11.347 & 0.219 \\
April & 5.228 & 5.303 & 4.395 & 21.146 & 0.208 \\
May & 5.303 & 4.813 & 3.608 & 17.540 & 0.206 \\
June & 5.866 & 5.122 & 3.867 & 20.862 & 0.185 \\
July & 5.095 & 6.952 & 7.447 & 35.495 & 0.210 \\
August & 5.740 & 5.253 & 4.289 & 22.629 & 0.190 \\
September & 5.702 & 6.714 & 6.532 & 34.787 & 0.188 \\
October & 5.833 & 5.725 & 4.662 & 25.170 & 0.185 \\
November & 5.596 & 5.688 & 4.833 & 25.036 & 0.193 \\
December & 6.113 & 6.048 & 5.093 & 28.906 & 0.176 \\
Yearly & 5.496 & 5.266 & 3.902 & 19.752 & 0.198 \\
\hline
\end{tabular}


The monthly wind parameters of the three proposed models are also compared (as seen in Figure 2, Figure 3, and Figure 4). The parameters for 2019 are very different from other years, and this is due to climate change which changes the wind speed. Changes in wind speed are not followed by changes in wind parameters properly. Changes in wind speed parameters can result in changes in the wind distribution functions. As shown in Figure 2, Figure 3, and Figure 4, changes in parameters occur in March, May, July, and the following months, wherein these months have a significant difference in temperature in 2019 compared to the other years.

Furthermore, comparisons of the performances of three distribution models for 2017, 2018, and 2019 by using the estimated parameters are shown in Figure 5, Figure 6, and Figure 7. The difference between the three models is very significant, especially in the exponential distribution model. This is due to the exponential distribution model only takes into account the scale factor, while the Weibull and gamma distributions use both scale and shape factors.
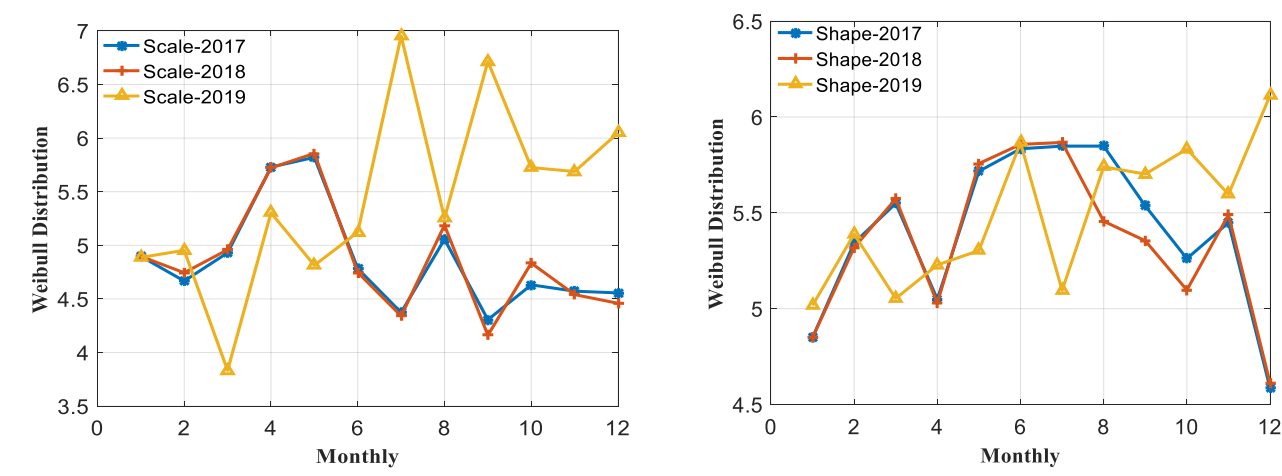

Figure 2. Estimated parameters of the Weibull distribution for three years


Figure 3. Estimated parameters of the gamma distribution for three years

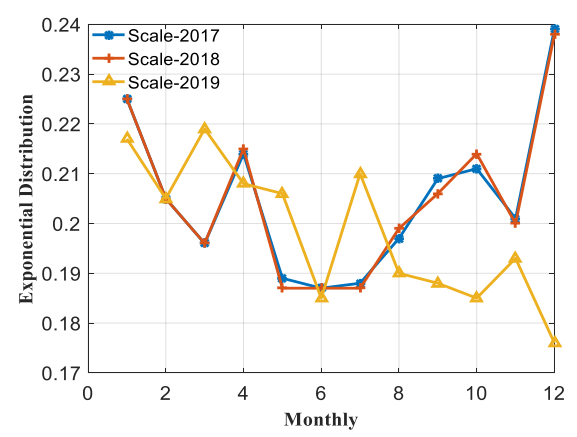

Figure 4. Estimated parameters of the exponential distribution for three years 


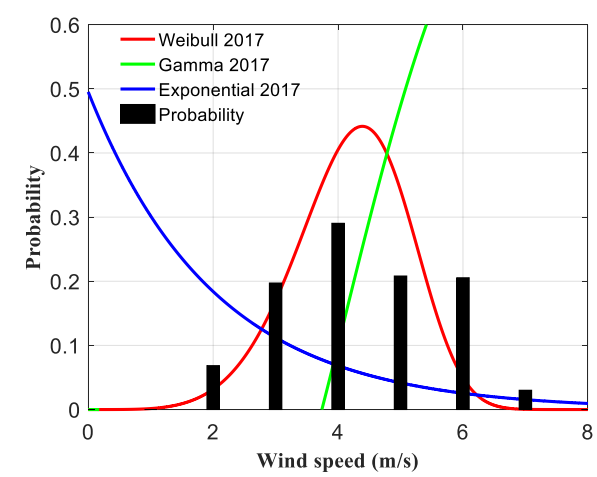

Figure 5. Comparison of three distribution models for 2017

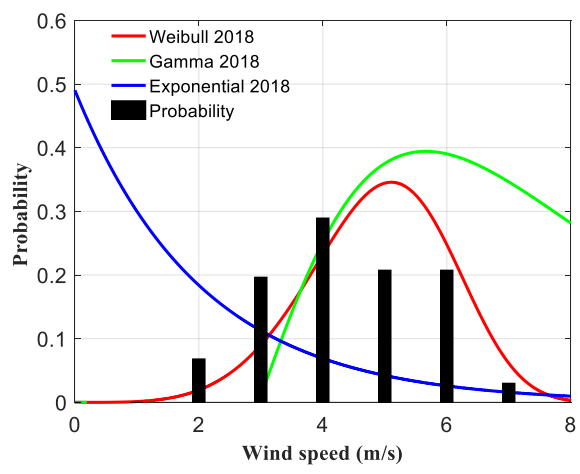

Figure 6. Comparison of three distribution models for 2018

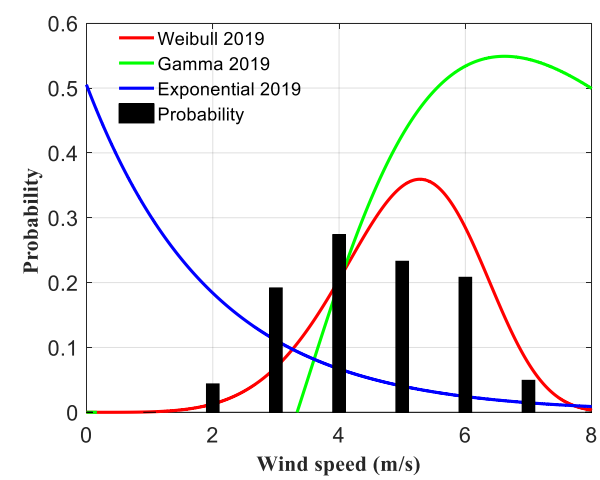

Figure7. Comparison of three distribution models for 2019

The observed and expected cumulative probability for the three models in 2017, 2018, and 2019 are presented in Figure 8, Figure 9, and Figure 10, respectively. The expected cumulative probability of wind characteristics is a straight line and it is used as a data benchmark. Further investigations found that the exponential model is not around a straight line. This occurs because of the fluctuations in wind speed data due to climate change.

From scale and shape factors and distribution probability results, the PDF and CDF of wind speed characteristics for Medan City are analyzed. For wind speed characteristic in 2017 (as seen in Figure 11), it is found that Weibull distribution PDF and CDF are 0.365 and 58\%, respectively, with the wind speed of 5.2 $\mathrm{m} / \mathrm{s}$. Gamma distribution gives PDF of 0.009 and CDF of $0.02 \%$, with the wind speed of $7.2 \mathrm{~m} / \mathrm{s}$, while exponential distribution PDF and CDF are 0.045 and 74\%, respectively, with the wind speed of $7.2 \mathrm{~m} / \mathrm{s}$.

For wind speed characteristic in 2018 (as seen in Figure 12), the Weibull distribution PDF and CDF are 0.348 and $57 \%$, respectively, with the wind speed of $5.2 \mathrm{~m} / \mathrm{s}$, while the gamma distribution gives PDF of 0.000007 and CDF of $4 \%$, with the wind speed of $7.2 \mathrm{~m} / \mathrm{s}$. In this case, the exponential distribution PDF and CDF are 0.046 and $77.5 \%$, respectively, with the wind speed of $7.2 \mathrm{~m} / \mathrm{s}$.

For wind speed characteristic in 2019 (as seen in Figure 13), the PDF and CDF obtained by the Weibull distribution model are 0.345 and $51 \%$, respectively, with a wind speed of $5.2 \mathrm{~m} / \mathrm{s}$. In the same case, the gamma distribution gives PDF of 0.09 and CDF of $3 \%$, with the wind speed of $7.2 \mathrm{~m} / \mathrm{s}$, while the exponential distribution gives PDF and CDF of 0.048 and $73.0 \%$, respectively, with the wind speed of 7.2 $\mathrm{m} / \mathrm{s}$.

In addition, the PDF and CDF of the Weibull, gamma, and exponential distribution models are tabulated as in Table 4. Table 4 shows that the Weibull distribution is the best model to determine PDF, followed by the exponential and gamma distributions. On the other hand, the exponential distribution is the best model to determine CDF, followed by the Weibull and gamma distributions. 

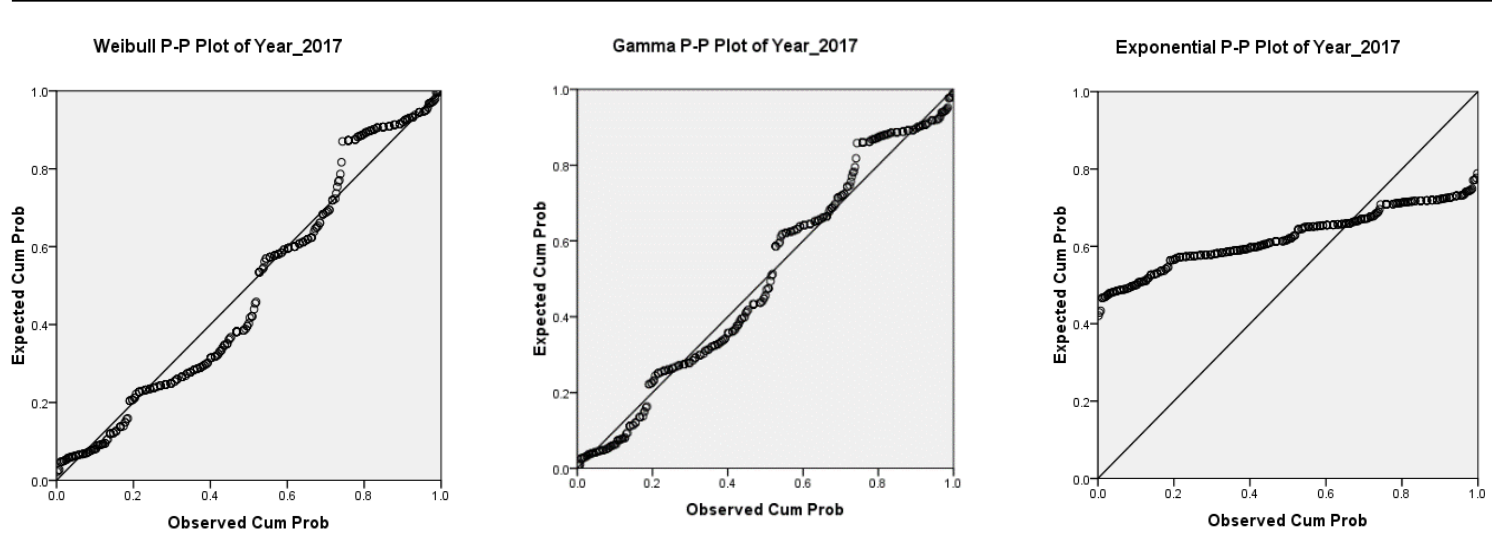

Figure 8. Observed and expected cumulative probability for the three models in 2017
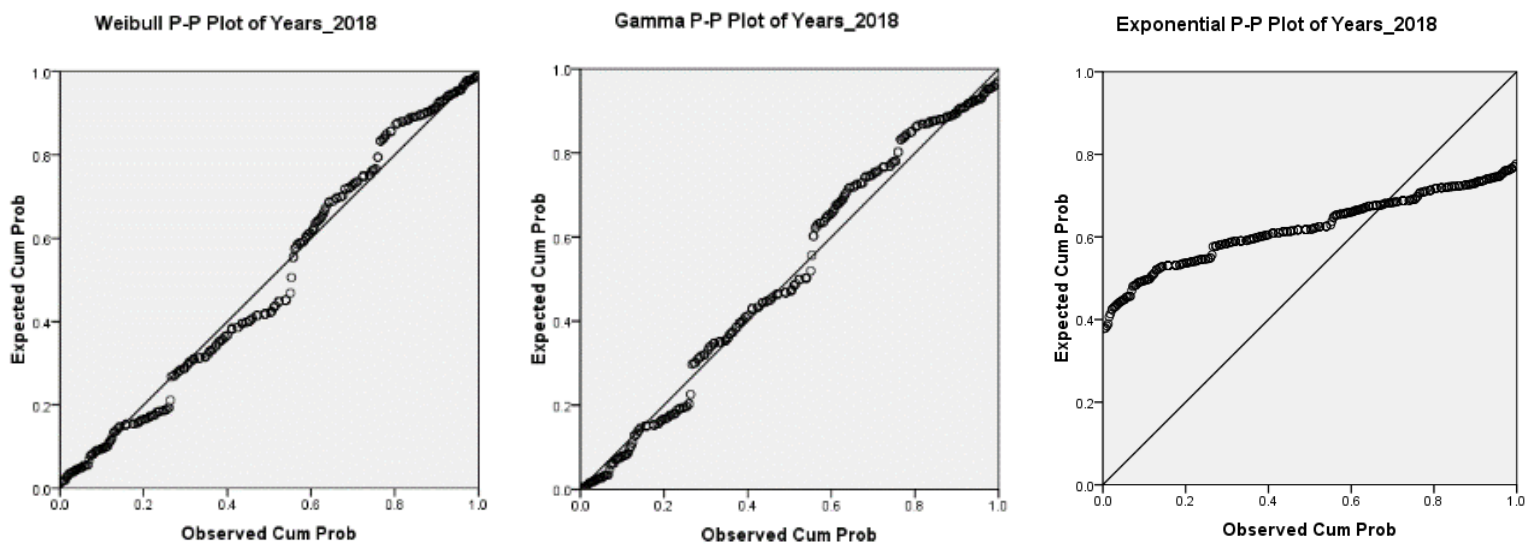

Figure 9. Observed and expected cumulative probability for the three models in 2018
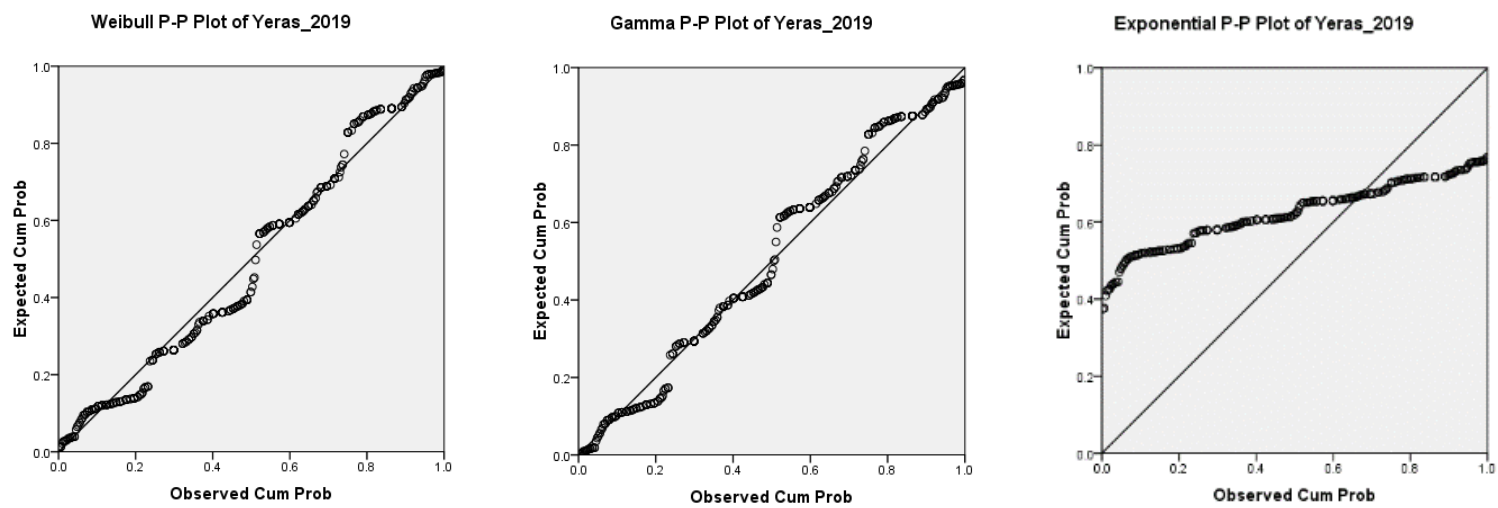

Figure 10. Observed and expected cumulative probability for the three models in 2019

Table 4. Comparison PDF and CDF for three models

\begin{tabular}{ccccccc}
\hline & \multicolumn{2}{c}{ Weibull model } & \multicolumn{2}{c}{ Gamma model } & \multicolumn{2}{c}{ Exponential model } \\
& PDF & CDF $(\%)$ & PDF & CDF (\%) & PDF & CDF $(\%)$ \\
\hline 2017 & 0.365 & 58.0 & 0.009 & 0.02 & 0.045 & 74.0 \\
2018 & 0.348 & 57.0 & 0.000007 & 4.00 & 0.046 & 77.5 \\
2019 & 0.345 & 51.0 & 0.09 & 3.00 & 0.048 & 73.0 \\
\hline
\end{tabular}



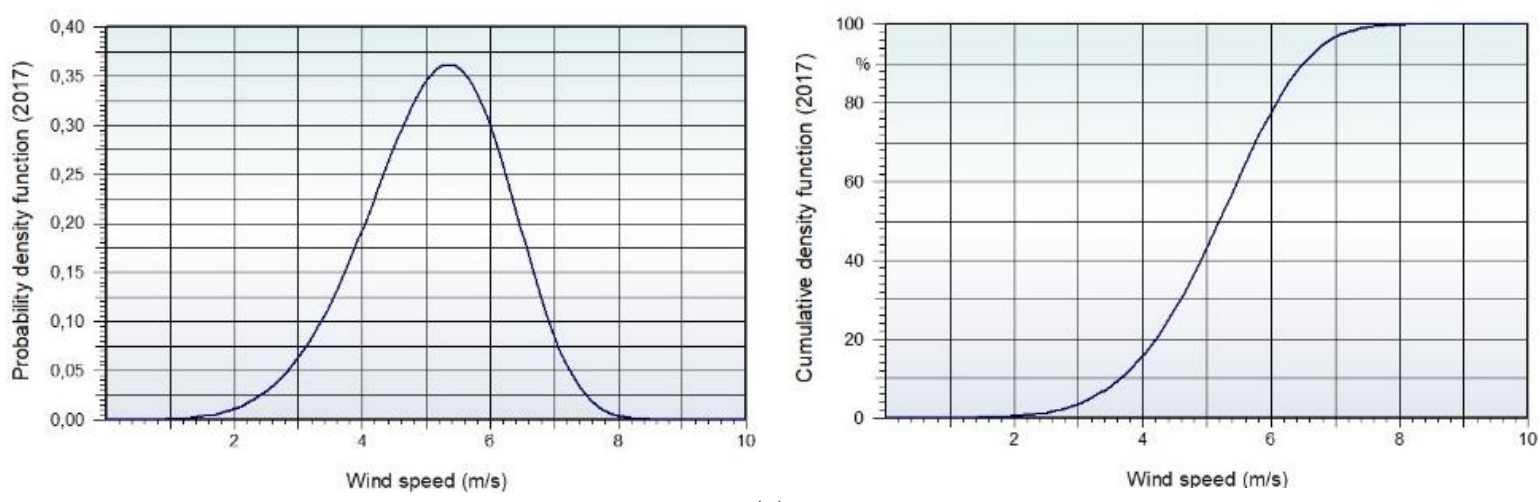

(a)
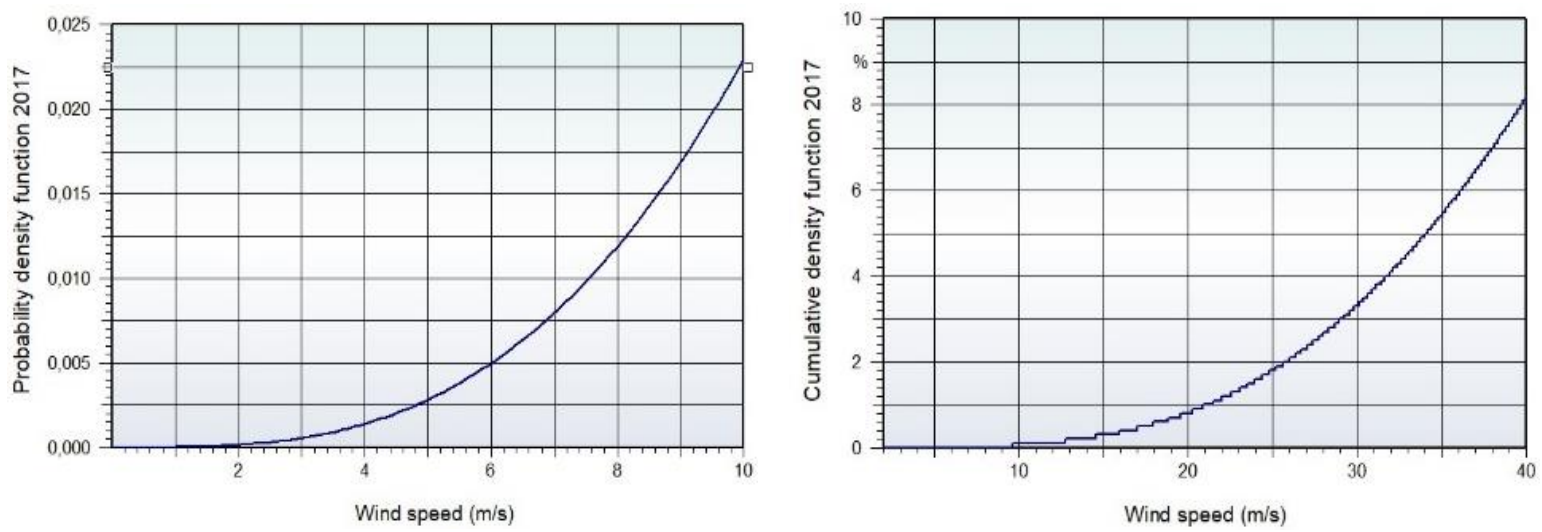

(b)
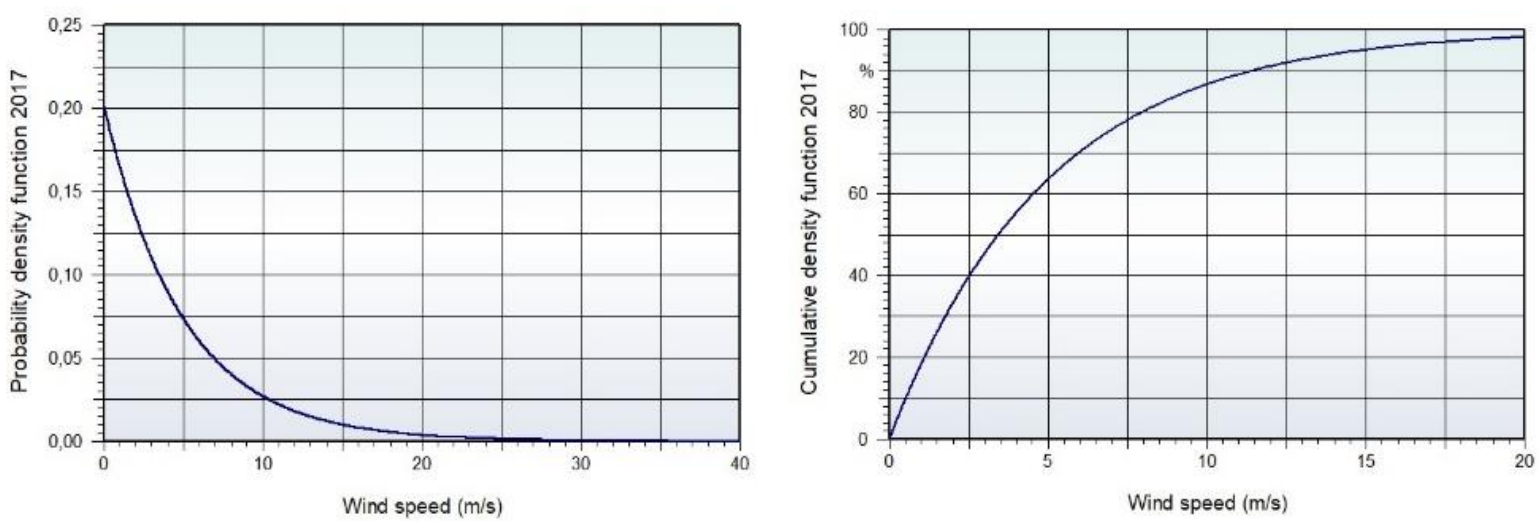

(c)

Figure 11. PDF and CDF: (a) Weibull, (b) gamma, (c) exponential distribution models for 2017 

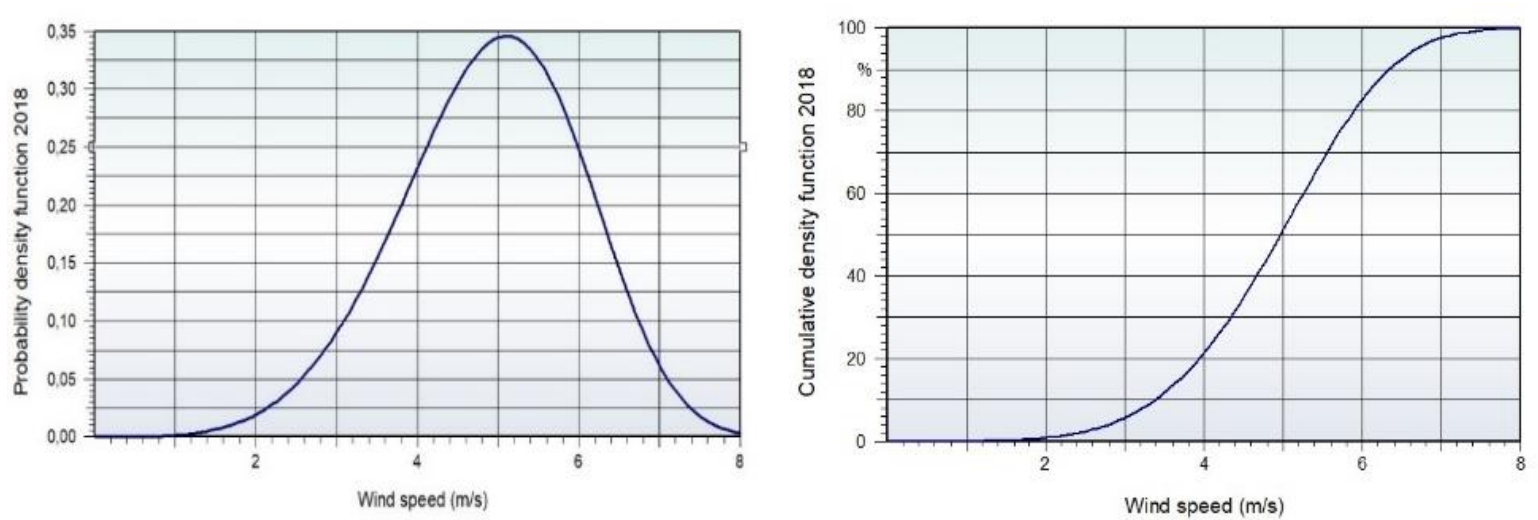

(a)
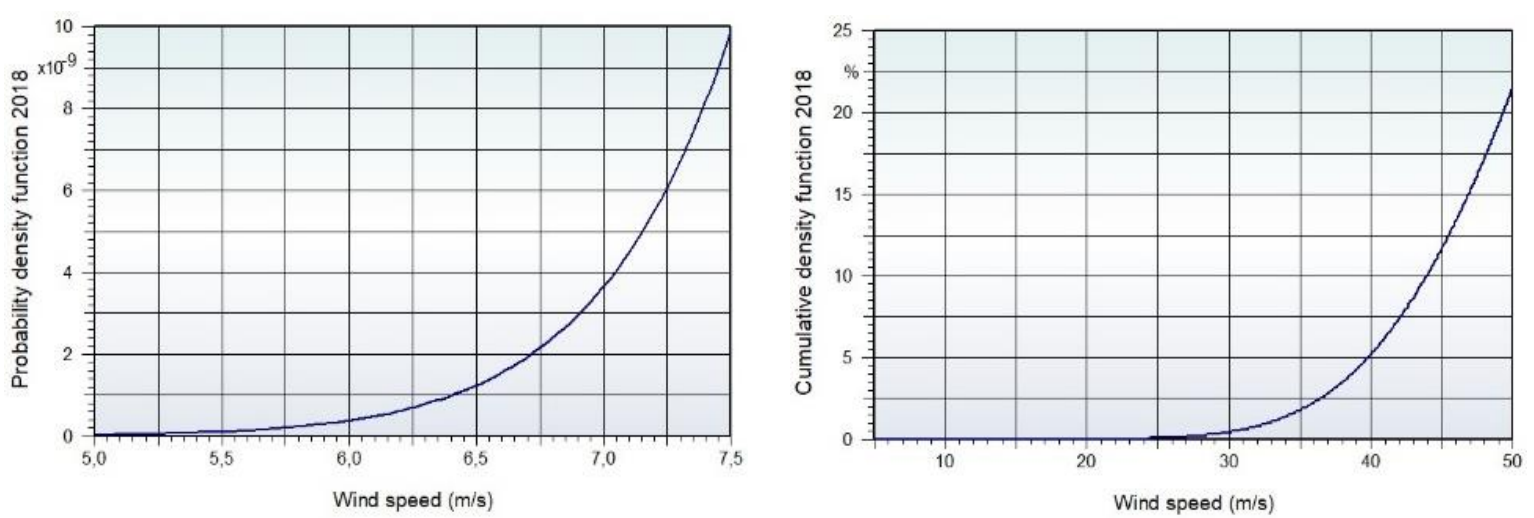

(b)
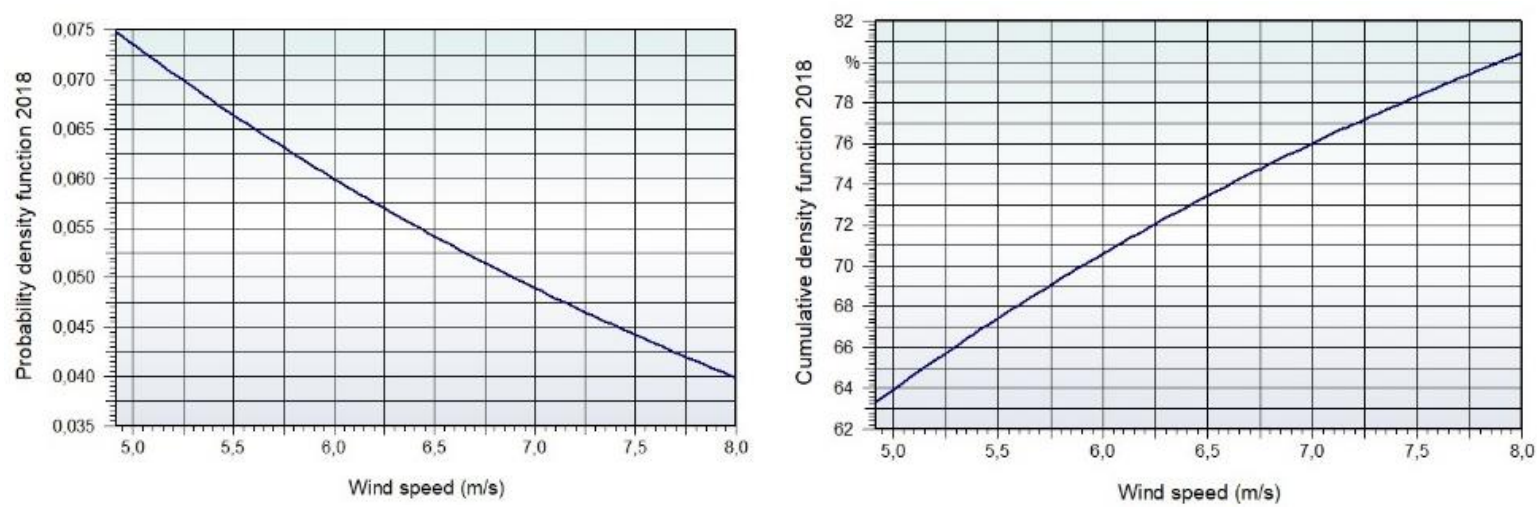

(c)

Figure 12. PDF and CDF: (a) Weibull, (b) gamma, (c) exponential distribution models for 2018 


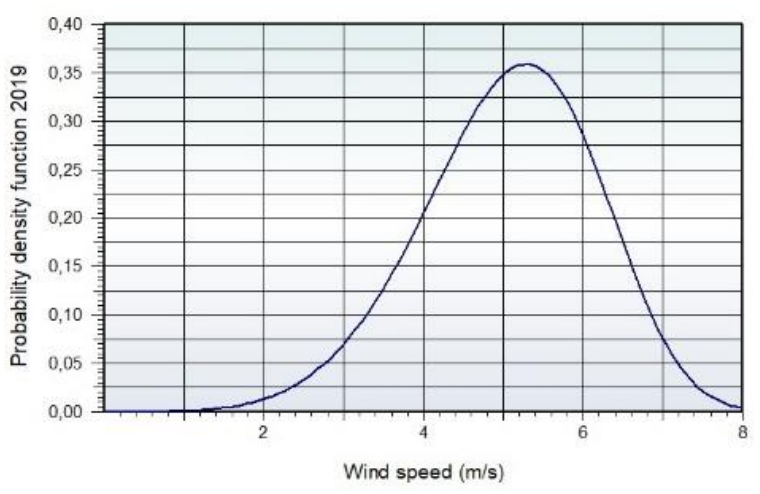

(a)
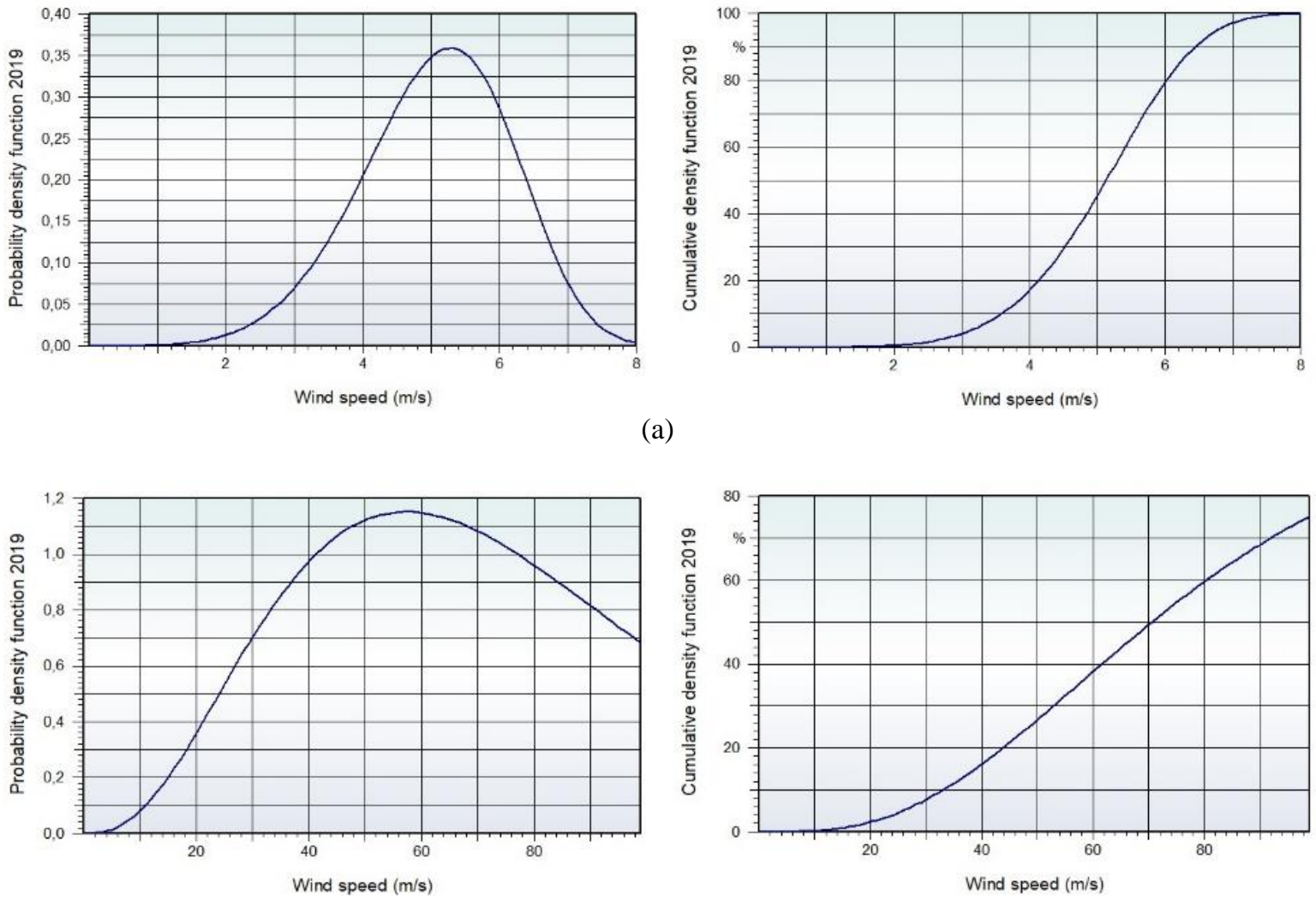

(b)
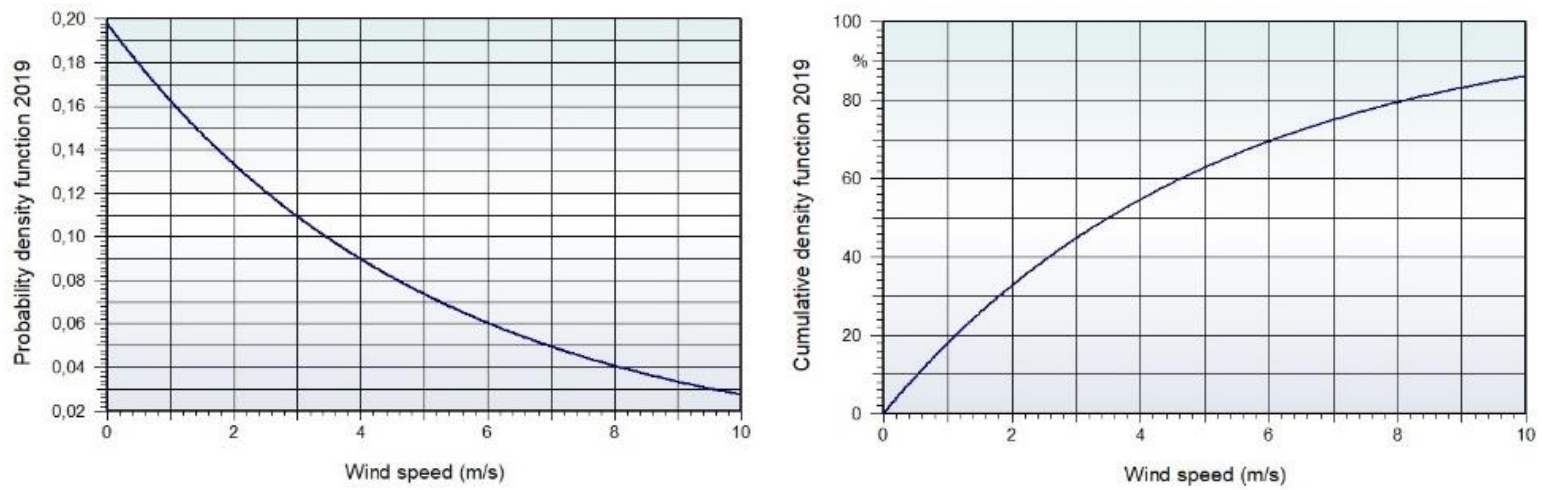

(c)

Figure 13. PDF and CDF: (a) Weibull, (b) gamma, (c) exponential distribution models for 2019

\section{CONCLUSION}

Three different models have been applied to estimate parameters and distribution functions of wind speed in Medan City. Comparisons of the performances of three distribution models for 2017, 2018, and 2019 wind data showed that the exponential model performed very differently from the Weibull and gamma models. The observed cumulative probability of wind characteristics by using the exponential model did not fit the expected values. However, the exponential distribution was found as the best model to determine CDF, followed by the Weibull and gamma distributions. On the other hand, the Weibull distribution was the best model to determine PDF. The gamma model gave the worst performances in determining both CDF and PDF values.

\section{REFERENCES}

[1] F. Fazelpour, et al., "Wind energy potential and economic assessment of four locations in Sistan and Balouchestan province in Iran," Renewable Energy, vol. 109, pp. 646-667, 2017, DOI: 10.1016/j.renene.2017.03.072. 
[2] IRENA, 2020, "Renewable capacity statistics 2020”, International Renewable Energy Agency (IRENA). [Online]. Available: https://irena.org/publications/2020/Mar/Renewable-Capacity-Statistics-2020

[3] A. Bahrami, et al., "Assessing the feasibility of wind energy as a power source in Turkmenistan; a major opportunity for Central Asia's energy market," Energy, vol. 183, pp. 415-427, 2019, DOI: 10.1016/j.energy.2019.06.108.

[4] A. S. A. Badawi, et al., "Practical electrical energy production to solve the shortage in electricity in Palestine and Pay Back period," International Journal of Electrical and Computer Engineering, vol. 9, no. 6, pp. 4610-4616, 2019, DOI: 10.11591/ijece.v9i6.pp4610-4616.

[5] T. P. Chang, "Performance comparison of six numerical methods in estimating Weibull parameters for wind energy application," Applied Energy, vol. 88, no. 1, pp. 272-282, 2011, DOI: 10.1016/j.apenergy.2010.06.018.

[6] W. O. Mufutau, et al., "Wind speed data analysis and assessment of wind energy potential of Abeokuta and IjebuOde, Ogun State, southwestern Nigeria," Journal of Scientific and Engineering Research, vol. 5, no. 5, pp.499-510, 2018.

[7] S. Singh, et al., "A review of wind-resource-assessment technology," Journal of Energy Engineering, vol. 132, no. 1, pp. 8-14, 2006, DOI: 10.1061/(ASCE)0733-9402(2006)132:1(8).

[8] M. Sumair, et al., "Extrapolation of wind data using generalized versus site-specific wind power law for wind power production prospective at Shahbandar- a coastal site in Pakistan," Energy Exploration \& Exploitation, pp. 117, 2020, DOI: $10.1177 / 0144598720952507$.

[9] P. Kiss and I. M. Jánosi, "Comprehensive empirical analysis of ERA-40 surface wind speed distribution over Europe," Energy Conversion and Management, vol. 49, no. 8, pp. 2142-2151, 2008, DOI: 10.1016/j.enconman.2008.02.003.

[10] M. R. Islam, et al., "Assessment of wind energy potentiality at Kudat and Labuan, Malaysia using Weibull distribution function," Energy, vol. 36, no. 2, pp. 985-992, 2011, DOI: 10.1016/j.energy.2010.12.011.

[11] T. Gulersoy and N. S. Çetin, "Menemen bölgesinde rüzgar türbinleri için Rayleigh ve Weibull dăğlımlarının kullanılmas1," Politeknik Dergisi, vol. 13, 3, pp. 209-213, 2010.

[12] L. Bilir, et al., "An investigation on wind energy potential and small scale wind turbine performance at İncek region-Ankara, Turkey," Energy Conversion and Management, vol. 103, pp. 910-923, 2015, DOI: 10.1016/j.enconman.2015.07.017.

[13] A. Ezzaidi, et al., "Evaluation of the energy performance of the Amougdoul wind farm, Morocco," International Journal of Electrical and Computer Engineering, vol. 7, no. 2, pp. 692-705, 2017, DOI: 10.11591/ijece.v7i2.pp692-705 .

[14] M. Sumair, et al., "Investigation of wind shear coefficients and their effect on annual energy yields along the coastal sites of Pakistan," Energy Exploration \& Exploitation, pp. 1-12, 2020, DOI: 10.1177/0144598720930422.

[15] M. Sumair, et al., "Efficiency comparison of historical and newly developed Weibull parameters estimation methods," Energy Exploration \& Exploitation, 1-22, 2020, DOI: 10.1177/0144598720959758 .

[16] M. Carrasco-Díaz, et al., "An assessment of wind power potential along the coast of Tamaulipas, northeastern Mexico,” Renewable Energy, vol. 78, pp. 295-305, 2015, DOI: 10.1016/j.renene.2015.01.007.

[17] Z. R. Shu, et al., "Statistical analysis of wind characteristics and wind energy potential in Hong Kong," Energy Conversion and Management, vol. 101, pp. 644-657, 2015, DOI: 10.1016/j.enconman.2015.05.070.

[18] D. Mohammed, et al., "Wind speed data and wind energy potential using Weibull distribution in Zagora, Morocco," International Journal of Renewable Energy Development, vol. 8, no. 3, pp. 267-273, 2019, DOI: 10.14710/ijred.8.3.267-273.

[19] F. H. Mahmood, et al., "Wind characteristic analysis based on Weibull distribution of Al-Salman site, Iraq," Energy Reports, vol. 6, pp. 79-87, 2020, DOI: 10.1016/j.egyr.2019.10.021.

[20] E. K. Akpinar and S. Akpinar, "Statistical analysis of wind energy potential on the basis of the Weibull and Rayleigh distributions for Agin-Elazig, Turkey," Proceedings of the Institution of Mechanical Engineers, Part A: Journal of Power and Energy, vol. 218, no. 8, pp. 557-565, 2004, DOI: 10.1243/0957650042584357.

[21] J. A. Carta and P. Ramirez, "Analysis of two-component mixture Weibull statistics for estimation of wind speed distributions," Renewable Energy, vol. 32, no. 3, pp. 518-531, 2007, DOI: 10.1016/j.renene.2006.05.005.

[22] T. P. Chang, "Estimation of wind energy potential using different probability density functions," Applied Energy, vol. 88, no. 5, pp. 1848-1856, 2011, DOI: 10.1016/j.apenergy.2010.11.010.

[23] W. Werapun, et al., "Comparative study of five methods to estimate Weibull parameters for wind speed on Phangan Island, Thailand,” Energy Procedia, vol. 79, pp. 976-981, 2015, DOI: 10.1016/j.egypro.2015.11.596.

[24] A. Bahrami, et al., "Technical and economic analysis of wind energy potential in Uzbekistan," Journal of Cleaner Production, vol. 223, pp. 801-814, 2019, DOI: 10.1016/j.jclepro.2019.03.140.

[25] A. Teimourian, et al., "Assessment of wind energy potential in the southeastern province of Iran," Energy Sources, Part A: Recovery, Utilization, and Environmental Effects, vol. 42, no. 3, pp. 329-343, 2019, DOI: 10.1080/15567036.2019.1587079.

[26] M. Sumair, et al., "Wind potential estimation and proposed energy production in Southern Punjab using Weibull probability density function and surface measured data," Energy Exploration \& Exploitation, pp. 1-19, 2020, DOI: $10.1177 / 0144598720920748$.

[27] M. Sumair, et al., "Comparison of three probability distributions and techno-economic analysis of wind energy production along the coastal belt of Pakistan," Energy Exploration \& Exploitation, pp. 1-23, 2020, DOI: $10.1177 / 0144598720931587$. 
[28] I. Mert and C. Karakuş, "A statistical analysis of wind speed data using Burr, generalized gamma, and Weibull distributions in Antakya, Turkey," Turkish Journal of Electrical Engineering \& Computer Sciences, vol. 23, no. 6, pp. 1571-1586, 2015, DOI: 10.3906/elk-1402-66.

[29] S. A. Akdağ, et al., "Use of two-component Weibull mixtures in the analysis of wind speed in the Eastern Mediterranean," Applied Energy, vol. 87, no. 8, pp. 2566-2573, 2010, DOI: 10.1016/j.apenergy.2010.02.033.

[30] P. K. Chaurasiya, et al., "Evaluation of wind energy potential and estimation of wind turbine characteristics for two different sites," International Journal of Ambient Energy, pp. 1-11, 2019.

[31] M, Sumair, et al., "Application of five continuous distributions and evaluation of wind potential at five stations using normal distribution," Energy Exploration \& Exploitation, pp. 1-26, 2020, DOI: 10.1177/0144598720939373.

[32] R. Kollu, et al., "Mixture probability distribution functions to model wind speed distributions," International Journal of Energy and Environmental Engineering, vol. 3, no. 1, p. 27, 2012, DOI: 10.1186/2251-6832-3-27.

[33] W. E. Bardsley, "Note on the use of the inverse Gaussin distribution for wind energy applications," Journal of Applied Meteorology, vol. 19, no. 9, pp. 1126-1130, 1980.

[34] L. Van der Auwera, et al., "The use of the Weibull three-parameter model for estimating mean wind power densities," Journal of Applied Meteorology and Climatology, vol. 19, no. 7, pp. 819-825, 1980, DOI: 10.1175/1520-0450(1980)019<0819:TUOTWT>2.0.CO;2.

[35] B. G. Brown, et al., "Time series models to simulate and forecast wind speed and wind power," Journal of Applied Meteorology and Climatology, vol. 23, no. 8, pp. 1184-1195, 1984, DOI: /10.1175/15200450(1984)023<1184:TSMTSA >2.0.CO;2.

[36] F. G. Akgül, et al., "An alternative distribution to Weibull for modeling the wind speed data: Inverse Weibull distribution," Energy Conversion and Management, vol. 114, pp. 234-240, 2016, DOI: 10.1016/j.enconman.2016.02.026.

[37] S. Akpinar and E.K. Akpinar, "Wind energy analysis based on maximum entropy principle (MEP)-type distribution function," Energy Conversion and Management, vol. 48, no. 4, pp. 1140-1149, 2007, DOI: 10.1016/j.enconman.2006.10.004.

[38] O. A. M. Omar, "Commercial wind turbines modeling using single and composite cumulative probability density functions," International Journal of Electrical and Computer Engineering, vol. 11, no. 1, pp. 47-56, 2021, DOI: 10.11591/ijece.v11i1.pp47-56.

[39] N. A. Arreyndip, et al., "Wind energy potential assessment of Cameroon's coastal regions for the installation of an onshore wind farm," Heliyon, vol. 2, no. 11, p. e00187, 2016, DOI: 10.1016/j.heliyon.2016.e00187.

[40] M. Sumair, et al., "Weibull parameters estimation using combined energy pattern and power density method for wind resource assessment," Energy Exploration \& Exploitation, pp. 1-18, 2020, DOI: 10.1177/0144598720947483.

[41] D. Bonatz, et al., From distant tales: archaeology and ethnohistory in the highlands of Sumatra, Cambridge Scholars Publishing, 2009.

[42] Suwarno, et al., "Assessment of wind energy potential using Weibull distribution function as wind power plant in Medan, North Sumatra," International Journal of Simulation: Systems, Science \& Technology, vol. 17, no. 41, pp. 24.1-24.5, 2017, DOI: 10.5013/IJSSST.a.17.41.24

[43] D. Indhumathy, et al., "Estimation of Weibull parameters for wind speed calculation at Kanyakumari in India," International Journal of Innovative Research in Science, Engineering and Technology, vol. 3, no. 1, pp. 8340-8345, 2014.

[44] S. F. Khahro, et al., "Evaluation of wind power production prospective and Weibull parameter estimation methods for Babaurband, Sindh Pakistan," Energy Conversion and Management, vol. 78, pp. 956-967, 2014, DOI: 10.1016/j.enconman.2013.06.062.

[45] P. K. Chaurasiya, et al., "Study of different parameters estimation methods of Weibull distribution to determine wind power density using ground based Doppler SODAR instrument," Alexandria Engineering Journal, vol. 57, no. 4, pp. 2299-2311, 2018, DOI: 10.1016/j.aej.2017.08.008. 